Supporting Information

\title{
Selenium Redox Reactivity on Colloidal CdSe Quantum Dot Surfaces
}

Emily Y. Tsui, Kimberly H. Hartstein, and Daniel R. Gamelin

Department of Chemistry, University of Washington, Seattle, WA 98195-1700, United States

E-mail: gamelin@chem.washington.edu

\section{Experimental Methods}

General Considerations. Unless stated otherwise, all measurements and synthetic manipulations were carried out using standard Schlenk techniques under a nitrogen atmosphere, or in M. Braun or Vac gloveboxes under an atmosphere of purified nitrogen. Anhydrous THF and toluene were purified through columns of dried alumina. Unless stated otherwise, reagents were purchased from Sigma-Aldrich and used without further purification. Tributyltin hydride was distilled before use. Cadmium oxide was purchased from Strem and used without further purification. Lithium triethylborodeuteride $(1.0 \mathrm{M}$ in THF) was prepared from triethylborane (1.0 M in THF) and lithium deuteride. Cadmium oleate was prepared according to published procedures. ${ }^{1}$

Nanocrystal Synthesis. Zinc blende CdSe nanocrystals of various diameters were prepared by an adaptation of a previously reported heat-up synthesis method. ${ }^{2}$ As an example: CdO $(0.195 \mathrm{~g}, 1.52 \mathrm{mmol})$, oleic acid $(1.6 \mathrm{~mL}, 5 \mathrm{mmol})$, and octadecene (36 g) were combined in a three-necked round bottom flask equipped with a stir bar and condenser and degassed under vacuum at $115^{\circ} \mathrm{C}$ for $30 \mathrm{~min}$. Under nitrogen, the mixture was heated to $300^{\circ} \mathrm{C}$ until it became optically clear and colorless. The mixture was cooled to $115{ }^{\circ} \mathrm{C}$, and $\mathrm{SeO}_{2}(0.170$ g, $1.53 \mathrm{mmol}$ ) was added under nitrogen flow, and the mixture was heated to $240{ }^{\circ} \mathrm{C}$ for 10 min., becoming an orange solution. The reaction mixture was cooled to room temperature, and the nanocrystals were precipitated using ethanol and then washed via redispersion/precipitation with toluene/ethanol. For nanocrystals purified under air-free, anhydrous conditions, the crude reaction mixture was distilled to remove octadecene, then dispersed in anhydrous pentane and precipitated with anhydrous methyl acetate.

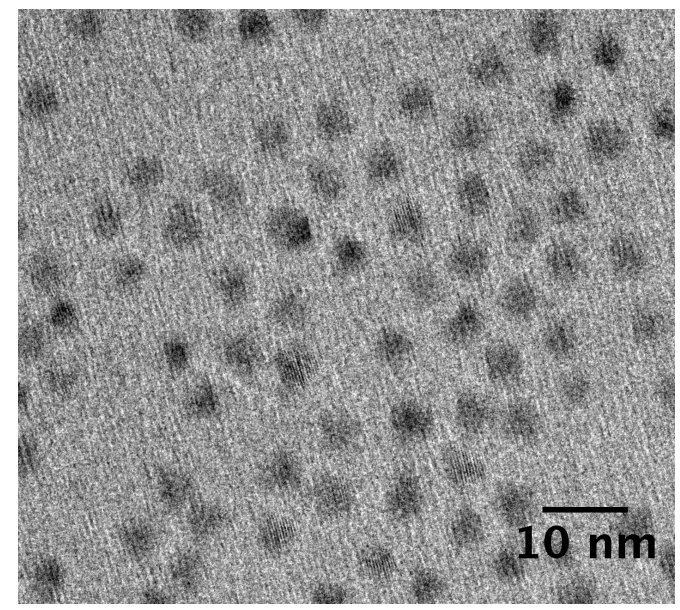

Figure S1. Representative TEM image of CdSe QDs. 
General Characterization. Nanocrystals were dried under vacuum, dispersed in anhydrous toluene or in anhydrous benzene- $d_{6}$, and stored in a dinitrogen glovebox. UV-vis spectra were measured of solutions in $1 \mathrm{~cm}$ air-free cuvettes sealed with Teflon stoppers using a Varian Cary 5000 spectrophotometer. For photoluminescence measurements, a sealable cuvette containing $3 \mathrm{~mL}$ of nanocrystal solution (band gap absorption $=0.1-0.2$ ) and 0,30 , 60 , or 90 equiv $\mathrm{Li}\left[\mathrm{Et}_{3} \mathrm{BH}\right]$ added as a $0.01 \mathrm{M}$ THF solution was prepared in a nitrogen-filled glovebox. Photoluminescence decay curves were measured by exciting the nanocrystals with the frequency-doubled output of a Ti:sapphire laser at a $2.53 \mathrm{MHz}$ repetition rate 400 $\mathrm{nm}, 200 \mu \mathrm{W}$ ). Decay curves were recorded using a monochromator and streak camera with an instrument response function of $\sim 15 \mathrm{ps}$.

NMR spectra were recorded on Bruker AV300 or Bruker AV500 instruments. ${ }^{1} \mathrm{H}$ NMR spectra were referenced to the solvent residual peak $\left(7.16 \mathrm{ppm}\right.$ for $\left.\mathrm{C}_{6} \mathrm{D}_{6}\right),{ }^{11} \mathrm{~B}$ NMR spectra were referenced to an external standard of neat $\mathrm{BF}_{3} \bullet \mathrm{OEt}_{2}(0.0 \mathrm{ppm})$, and ${ }^{31} \mathrm{P} \mathrm{NMR}$ spectra were referenced to an external standard of $85 \% \mathrm{H}_{3} \mathrm{PO}_{4}(0.0 \mathrm{ppm})$. EPR spectra were recorded on a Bruker EMX spectrometer at liquid nitrogen temperatures.

XPS spectra were taken on a Surface Science Instruments S-Probe photoelectron spectrometer. This instrument has a monochromatized $\mathrm{Al} \mathrm{K \alpha} \mathrm{X}$-ray source which was operated at $20 \mathrm{~mA}$ and $10 \mathrm{kV}$. The samples were prepared by dropcasting toluene solutions of the functionalized colloidal CdSe QDs onto silicon wafers. X-ray analysis area for these acquisitions was approximately $800 \mu \mathrm{m}$ across. Pressure in the analytical chamber during spectral acquisition was less than $5 \times 10^{-9}$ torr. Pass energy for survey and detail spectra (to calculate composition) was $150 \mathrm{eV}$. The take-off angle (the angle between the sample normal and the input axis of the energy analyzer) was $0^{\circ},\left(0^{\circ}\right.$ take-off angle $\cong 100 \AA$ sampling depth). Service Physics Hawk version 7 data analysis software was used to calculate the elemental compositions from peak areas above an inelastic scattering (Shirley) background.

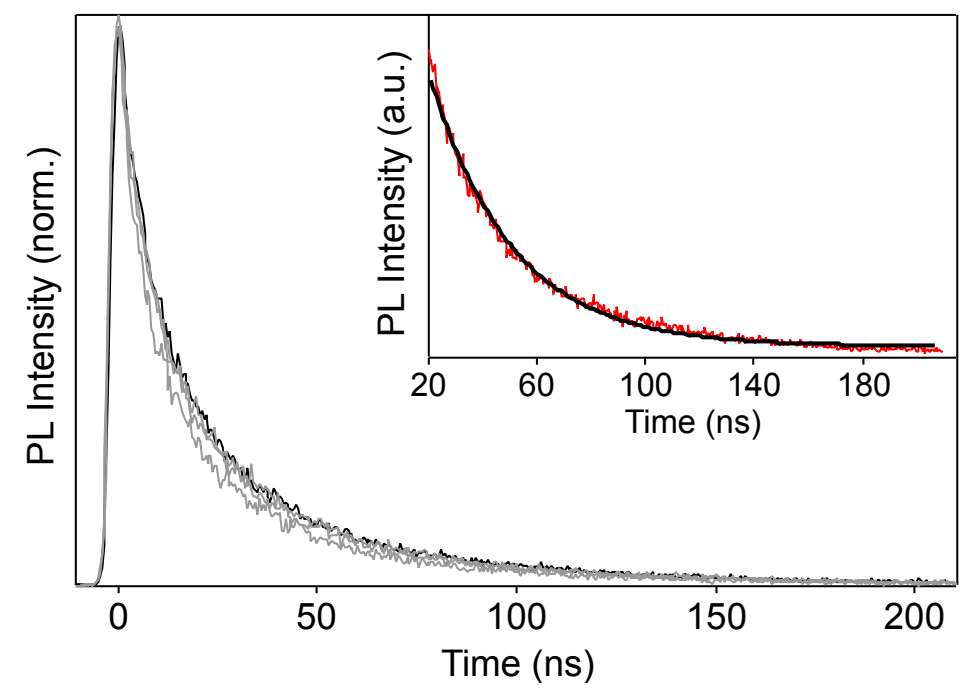

Figure S2. Normalized time-resolved PL from Figure 2 (main text). Inset: Time-resolved PL from a representative decay trace (red) with a single-exponential fit from 20-200 ns (black) to remove potential contributions from fast Auger decay processes. Decay time constants plotted in Figure 2 (main text) were fit using this time window for all decay traces. 
Photodoping. CdSe nanocrystals were photodoped as described previously. ${ }^{3}$ Typically, solutions of QDs in anhydrous toluene with 30-50 equivalents/QD of $\mathrm{Li}^{2} \mathrm{Et}_{3} \mathrm{BH}$ ] (added as a $0.01 \mathrm{M}$ solution in THF) were prepared anaerobically and loaded into an air-free cuvette. The nanocrystals were photodoped by illumination with a $100 \mathrm{~W} \mathrm{Hg} / \mathrm{Xe}$ Oriel photolysis lamp $\left(\sim 2 \mathrm{~W} / \mathrm{cm}^{2}, \sim 1.5 \mathrm{~cm}\right.$ illumination diameter $)$ using a $480 \mathrm{~nm}$ longpass filter. Absorption spectra were monitored during photodoping until the band-edge absorption stopped decreasing.

The data presented in Table 1 were collected as follows: in a nitrogen-filled glovebox, an air-free cuvette equipped with a stir bar was charged with a solution of CdSe QDs $(d \sim$ $3.6 \mathrm{~nm}, 1.8 \mu \mathrm{M}$ in toluene, $3 \mathrm{~mL}$ ). The corresponding reducing agent was added to the solution in the dark, and the cuvette was capped with a Teflon stopper. Using a Cary 5000 UV-vis-NIR spectrophotometer, spectra were collected at $1 \mathrm{~min}$. intervals while the sample was perpendicularly excited using a 5-mW 405-nm diode, typically for $15 \mathrm{~min}$. In some cases, photoexcitation was for a longer period of time, or a $100-\mathrm{W}$ photolysis lamp equipped with a 480-nm long pass filter was used instead.

Thermal tributyltin hydride reduction of CdSe QDs. In the glovebox, a Schlenk tube equipped with a stir bar was charged with a solution of CdSe QDs in toluene $(0.36 \mathrm{mM}, 3 \mathrm{~mL}, 1.1$ $\mu \mathrm{mol})$. Bu 3 SnH ( $60 \mu \mathrm{L}, 0.22 \mathrm{mmol}, 200$ equiv.) and AIBN ( $2 \mathrm{mg}, 0.011 \mathrm{mmol}, 10$ equiv) were added. The tube was sealed with a Teflon stopper, then heated in the dark at $60^{\circ} \mathrm{C}$ for $22 \mathrm{~h}$. The mixture was cooled to room temperature than dried in vacuo. Under nitrogen, the QDs were purified by two pentane-redispersion/methyl acetate-precipitation cycles and filtered to remove tin-containing side products. Figs. S11 and S12 plot XPS characterization and photodoping of these functionalized QDs.

Surface alkylation of CdSe QDs. Under ambient conditions, CdSe QDs described above (10 $\mathrm{mL}, 1.4 \times 10^{-4} \mathrm{M}$ in toluene, $d \sim 3.6 \mathrm{~nm}$ ) were treated with octadecylphosphonic acid (80 $\mathrm{mg}, 0.24 \mathrm{mmol}, 170$ equiv). The mixture was stirred for $3 \mathrm{~h}$ at room temperature, then the QDs were purified by 3 ethanol-precipitation/toluene-redispersion cycles. The QDs were dried under vacuum, brought into the glovebox, and resuspended in toluene. A sample of $0.7 \mu \mathrm{mol}$ of QDs in $4 \mathrm{~mL}$ toluene was treated with $100 \mu \mathrm{L} \operatorname{MesMgBr}(1.0 \mathrm{M}$ in ether, 140 equiv), and the mixture was stirred for $10 \mathrm{~min}$. at room temperature. 6-bromo-1-hexene (5 $\mu \mathrm{L}, 0.04 \mathrm{mmol}, 50$ equiv/QD) was added, and the mixture was transferred to a Schlenk tube equipped with a stir bar. The mixture was heated in the dark at $70^{\circ} \mathrm{C}$ for $18 \mathrm{~h}$, then dried in vacuo. The residue was dissolved in dichloromethane $(1 \mathrm{~mL})$, then precipitated from solution with ethanol. Concentrated $\mathrm{HCl}(4 \mathrm{~mL})$ was added to the pellet, then the mixture was sonicated for $1 \mathrm{~h}$. The acid solution was diluted using $5 \mathrm{~mL} \mathrm{H}_{2} \mathrm{O}$, and the organics were extracted using dichloromethane, dried over $\mathrm{MgSO}_{4}$, and filtered through a plug of silica gel. The filtrate was then analyzed using GC-MS, and the presence of the corresponding alkylated diselenide was confirmed using an authentic sample. ${ }^{4}$ No unreacted 6-bromo-1hexene was observed. The same procedure performed without treating the QDs with MesMgBr forms a small amount of diselenide (GC-MS), but in a much smaller ratio to unreacted 6-bromo-1-hexene. 


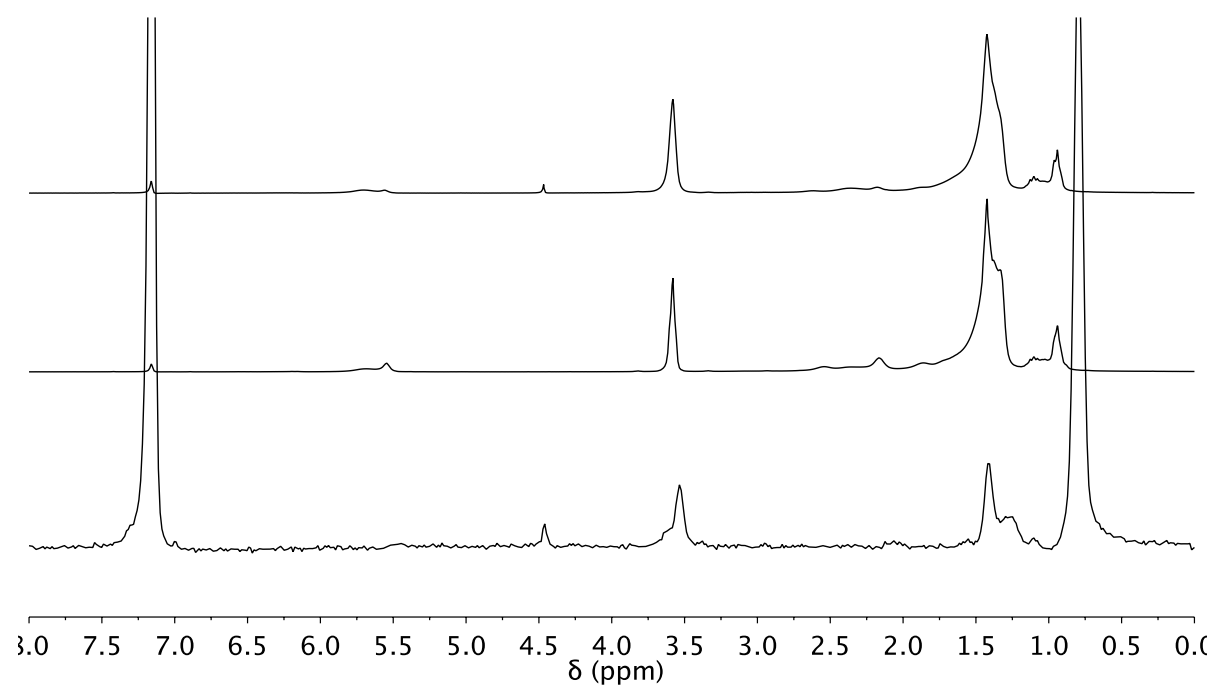

Figure S3. ${ }^{1} \mathrm{H}$ NMR spectrum at $25^{\circ} \mathrm{C}$ of CdSe QDs in $\mathrm{C}_{6} \mathrm{D}_{6}$ after addition of $\mathrm{Li}\left[\mathrm{Et} t_{3} \mathrm{BH}\right]$ (100 equiv) (top). ${ }^{1} \mathrm{H}$ NMR spectrum at $25{ }^{\circ} \mathrm{C}$ of CdSe QDs in $\mathrm{C}_{6} \mathrm{D}_{6}$ after addition of $\mathrm{Li}\left[\mathrm{Et}_{3} \mathrm{BD}\right]$ (100 equiv) (middle). ${ }^{2} \mathrm{H}$ NMR spectrum at $25^{\circ} \mathrm{C}$ of $\mathrm{CdSe}$ QDs in $\mathrm{C}_{6} \mathrm{H}_{6}$ after addition of $\mathrm{Li}_{[}\left[\mathrm{Et}_{3} \mathrm{BD}\right.$ ] (100 equiv). $\mathrm{D}_{2}$ is visible at $4.45 \mathrm{ppm}$, while other peaks arise from naturally abundant deuterium occurring in solvent (benzene and THF). Signal at $0.8 \mathrm{ppm}$ arises from an impurity in the $\mathrm{Li}_{[}\left[\mathrm{Et}_{3} \mathrm{BD}\right]$.

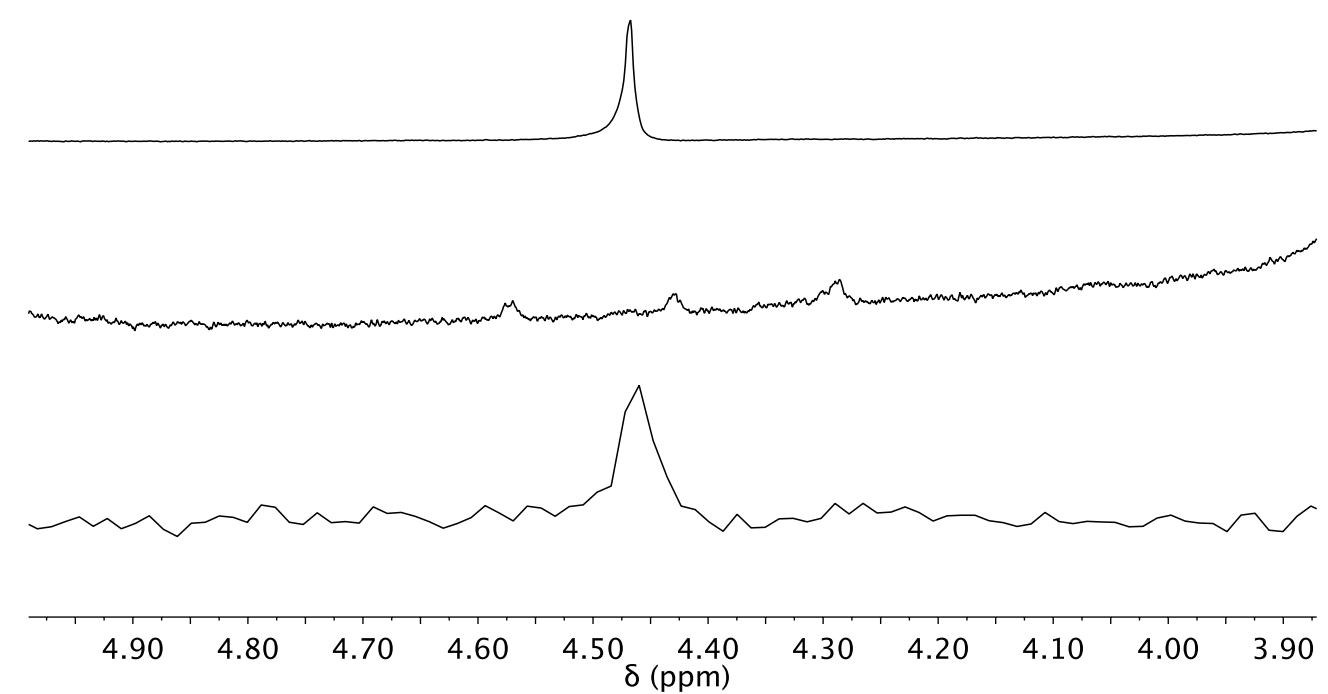

Figure S4. Expanded NMR spectra from Figure S1 showing $\mathrm{H}_{2}$ (top), HD (middle), and $\mathrm{D}_{2}$ (bottom). Only the singlet corresponding to $\mathrm{D}_{2}$ is observed in the ${ }^{2} \mathrm{H}$ NMR spectrum of CdSe QDs treated with $\left.\mathrm{Li}_{[\mathrm{Et}} \mathrm{BD}\right]$. No doublet corresponding to HD is detected, suggesting that $\mathrm{D}_{2}$ is formed preferentially to $\mathrm{HD}$. 


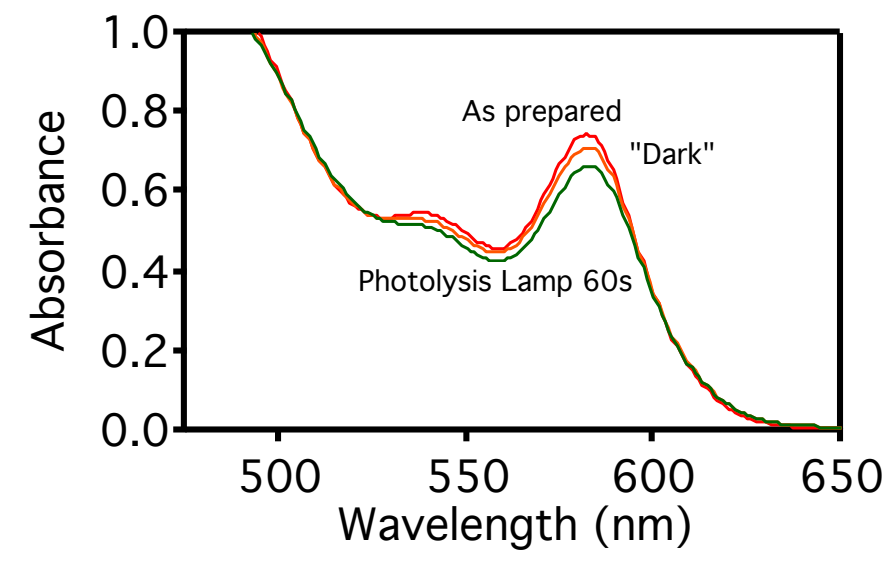

Figure S5. Absorption spectra of a mixture of CdSe QDs with excess sodium ethoxide $(10,000$ equiv./QD) in the dark and after photoexcitation.
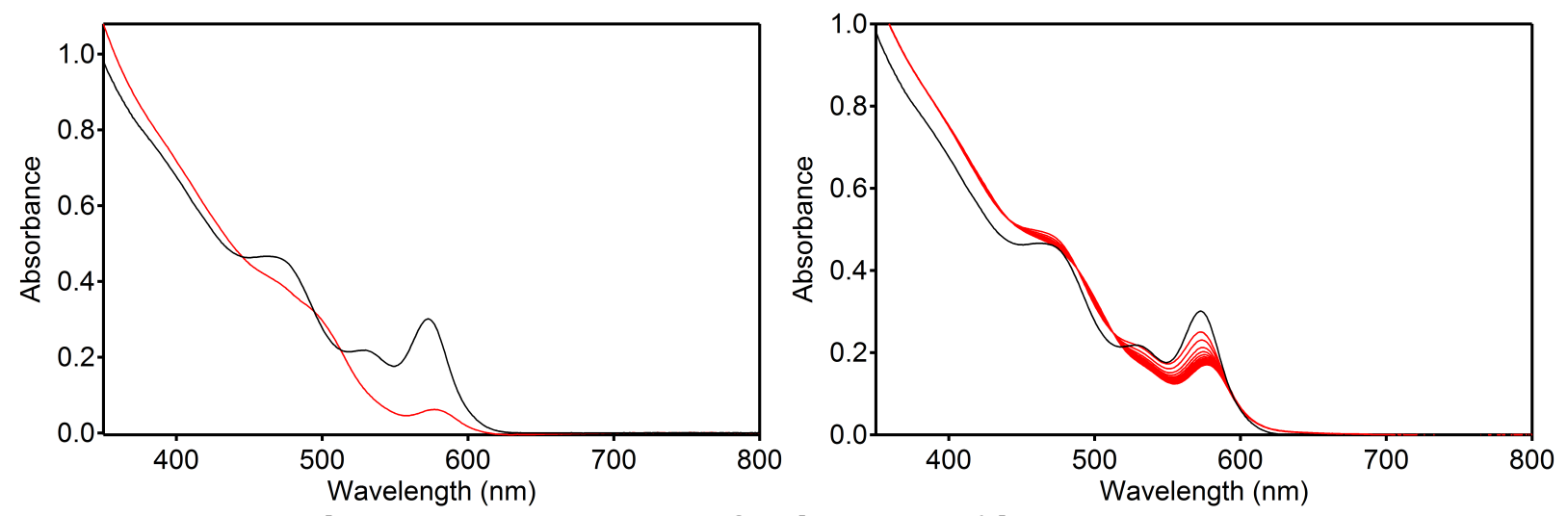

Figure S6. Absorption spectrum of CdSe QDs $(d \sim 3.6 \mathrm{~nm}, 1.8 \mu \mathrm{M}$ in $2: 1$ THF/toluene) before (black) and after (red) treatment with 60 equiv./QD of sodium naphthalenide in the dark (left). Absorption spectrum of CdSe QDs $(d \sim 3.6 \mathrm{~nm}, 1.8$ $\mu \mathrm{M}$ in 2:1 THF/toluene) before (black) and after (red) treatment with 40 equiv./QD of sodium naphthalenide in the dark followed by photoexcitation (right). 


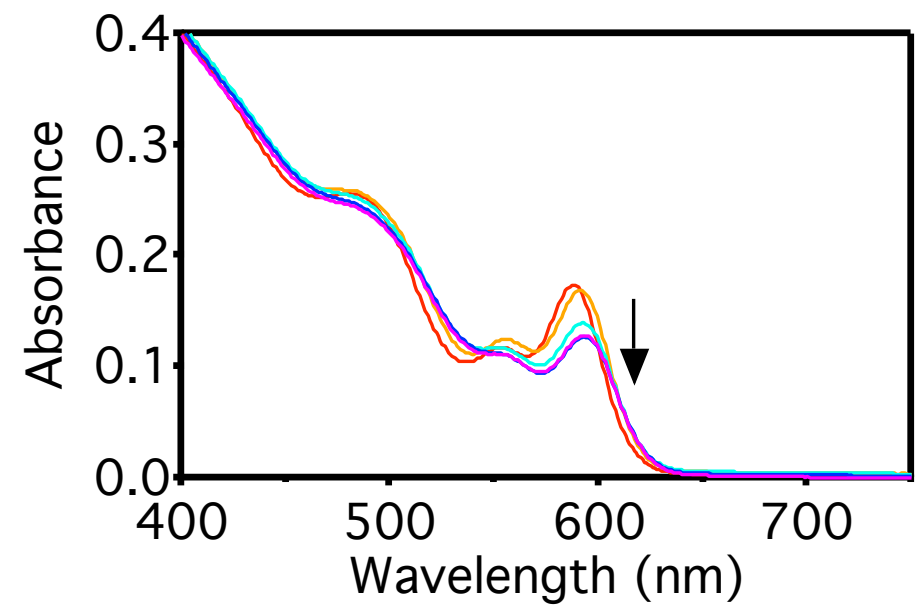

Figure S7. Absorption spectra of CdSe QDs after treatment with tributylphosphine (5000 equiv./QD) and a degassed aqueous solution of $\mathrm{NaOH}$ (10,000 equiv./QD) followed by photoexcitation.

A
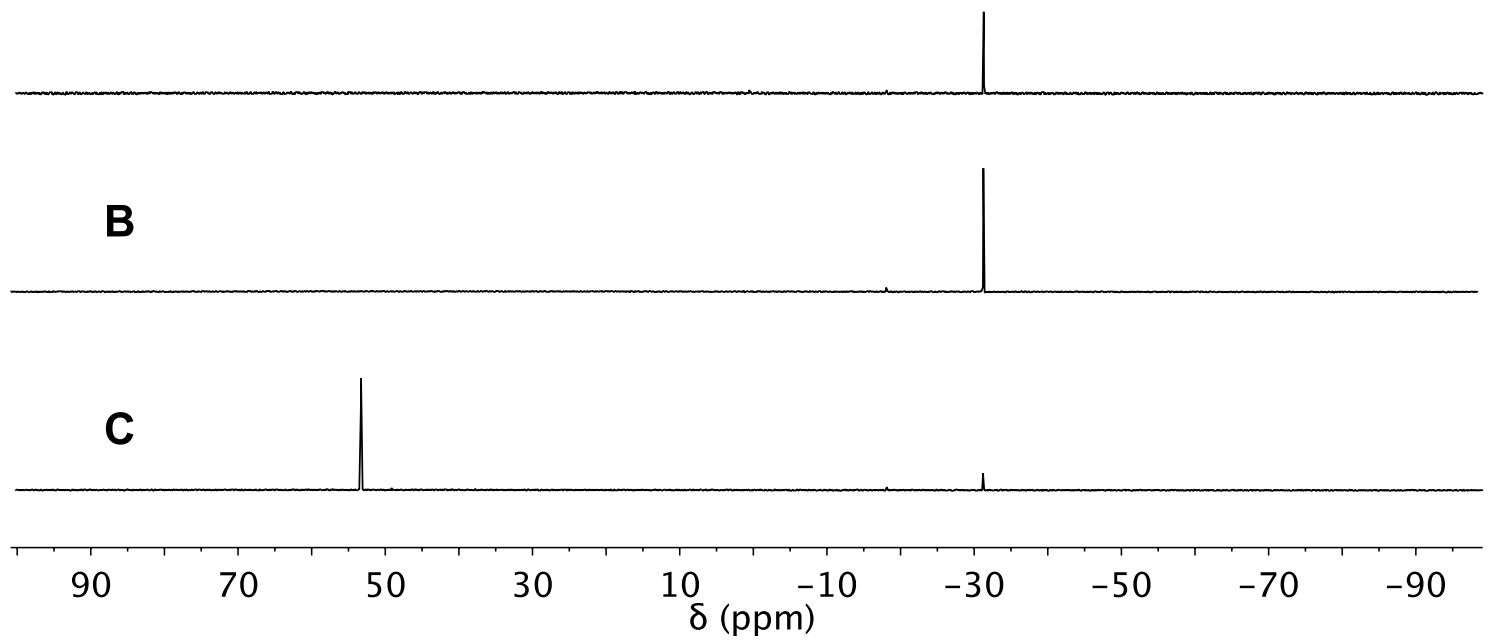

Figure S8. (A) ${ }^{31} \mathrm{P}$ NMR spectrum of $\mathrm{PBu}_{3}$ in THF. (B) ${ }^{31} \mathrm{P}$ NMR spectrum of a mixture of $\mathrm{PBu}_{3}$ and $\mathrm{PhSeSePh}$ in THF. (C) ${ }^{31} \mathrm{P}$ NMR spectrum of a mixture of $\mathrm{PBu}_{3}$, $\mathrm{PhSeSePh}$ (1 equiv), and $\mathrm{NaOH}$ (1.0 $\mathrm{M}$ in degassed $\mathrm{H}_{2} \mathrm{O}$, 2 equiv) after 20 min. at room temperature. The signal at $53 \mathrm{ppm}$ corresponds to $\mathrm{Bu}_{3} \mathrm{PO}$. 
A

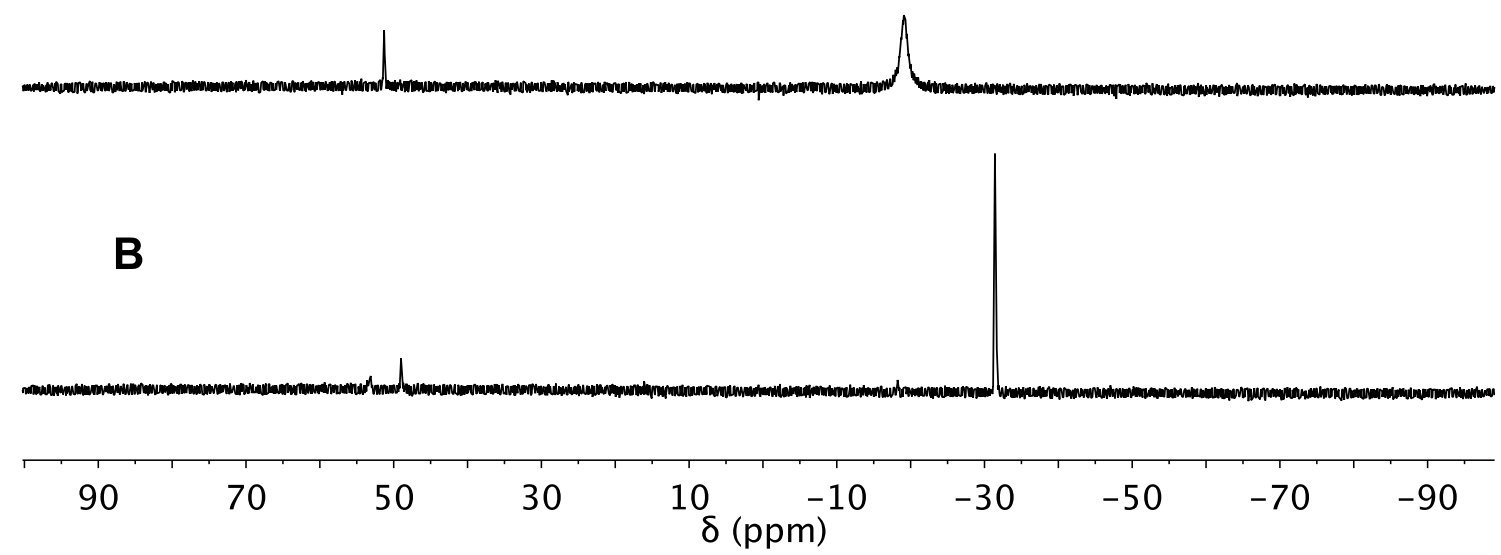

Figure S9. (A) ${ }^{31} \mathrm{P}$ NMR spectrum of a 2:1 THF/toluene mixture of cadmium oleate and $\mathrm{PBu}_{3}$ (2 equiv). (B) ${ }^{31} \mathrm{P}$ NMR spectrum of the same mixture with added $\mathrm{NaOH}$ (1.0 $\mathrm{M}$ in degassed $\mathrm{H}_{2} \mathrm{O}, 4$ equiv) after $20 \mathrm{~min}$. at room temperature. By integration, the mixture contains ca. $70 \%$ free $\mathrm{Bu}_{3} \mathrm{P}$, and an upper limit of $14 \% \mathrm{Bu}_{3} \mathrm{PO}$.

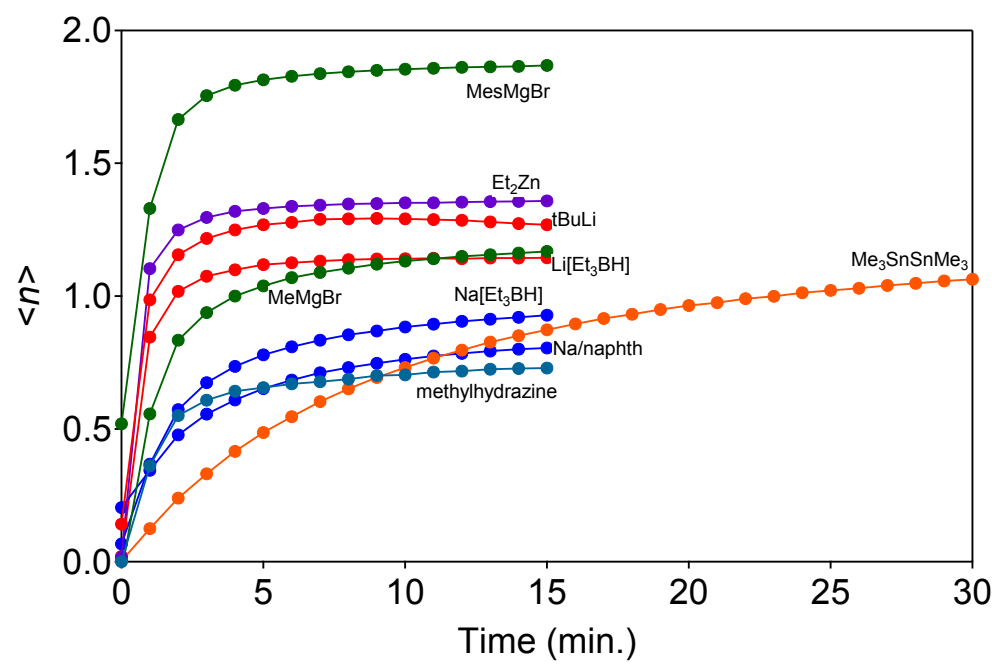

Figure S10. Average number of electrons per $Q D<n>$ estimated from $<n>=2\left(A_{0}-A\right) / A_{0}$ during photodoping of CdSe QDs $(d \sim 3.6 \mathrm{~nm}, 1.8 \mu \mathrm{M}$ in toluene or 2:1 THF/toluene) using different reductants over time under excitation with a 5mW 405-nm diode. 


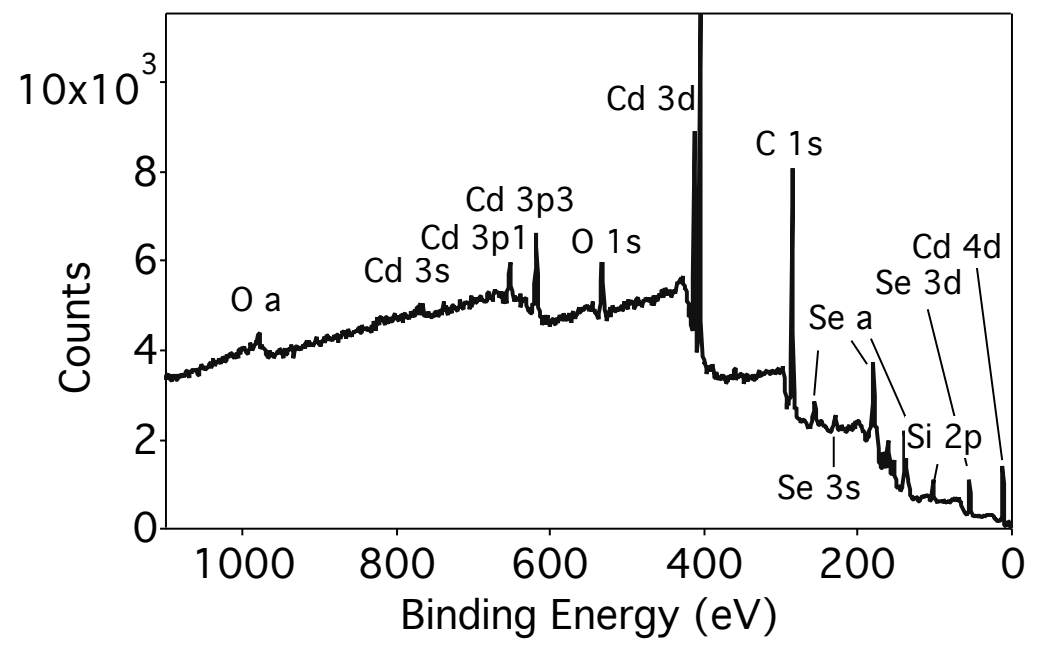

Figure S11. XPS survey spectrum of tin-functionalized CdSe QDs after washing and filtration to remove excess tin. CdSe QDs $(d \sim 3.6 \mathrm{~nm}, 1.1 \mu \mathrm{mol})$ were treated with $\mathrm{Bu}_{3} \mathrm{SnH}$ (200 equiv) and AIBN (10 equiv), then heated in the dark at $60^{\circ} \mathrm{C}$ for $22 \mathrm{~h}$.
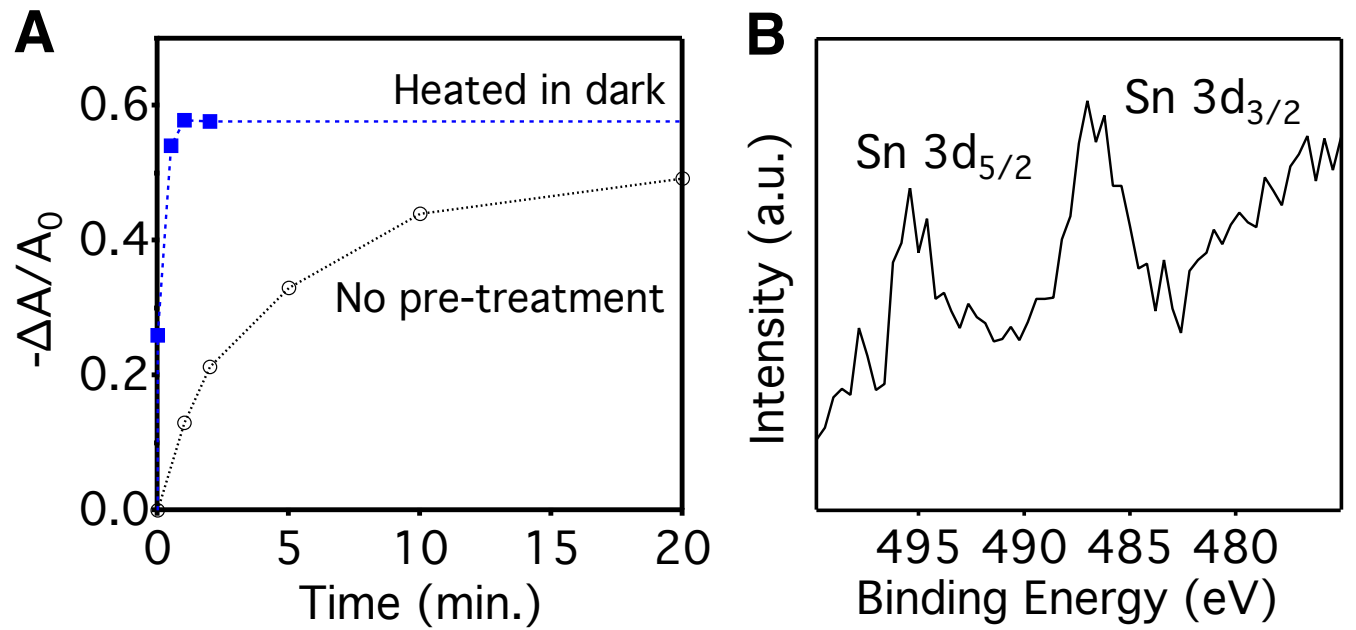

Figure S12. (A) Normalized first-exciton differential absorbance $\left(-\Delta A / A_{0}, \lambda=582\right.$ $\mathrm{nm})$ plotted $v s$ irradiation time for a solution of CdSe QDs in toluene $(1-2 \mu \mathrm{M}, d \sim$ $3.9 \mathrm{~nm}$ ) with added AIBN (10 equiv./QD) and $\mathrm{Bu}_{3} \mathrm{SnH}$ (5000 equiv./QD). Samples were irradiated immediately after mixing (black) or after first stirring in the dark at $60{ }^{\circ} \mathrm{C}$ for $22 \mathrm{~h}$ (blue). Dashed lines are guides to the eye. (B) Sn 3d X-ray photoelectron spectra (XPS) of $\mathrm{Bu}_{3} \mathrm{SnH}$-functionalized CdSe QDs on a Si substrate. XPS results indicate a $\sim 200: 1 \mathrm{Cd}: \mathrm{Sn}$ ratio, or approximately 2-3 Sn atoms per QD. 


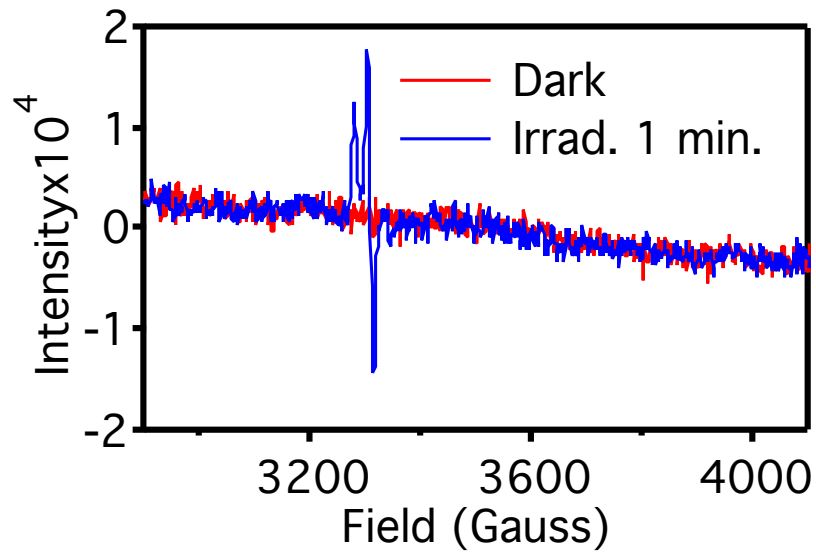

Figure S13. EPR spectra of a mixture of CdSe QDs $(d \sim 3.6 \mathrm{~nm}, 22 \mu \mathrm{M})$ and phenyl tert-butylnitrone $(0.25 \mathrm{M}, 10,000$ equiv) in toluene before (red) and after photoexcitation (blue).

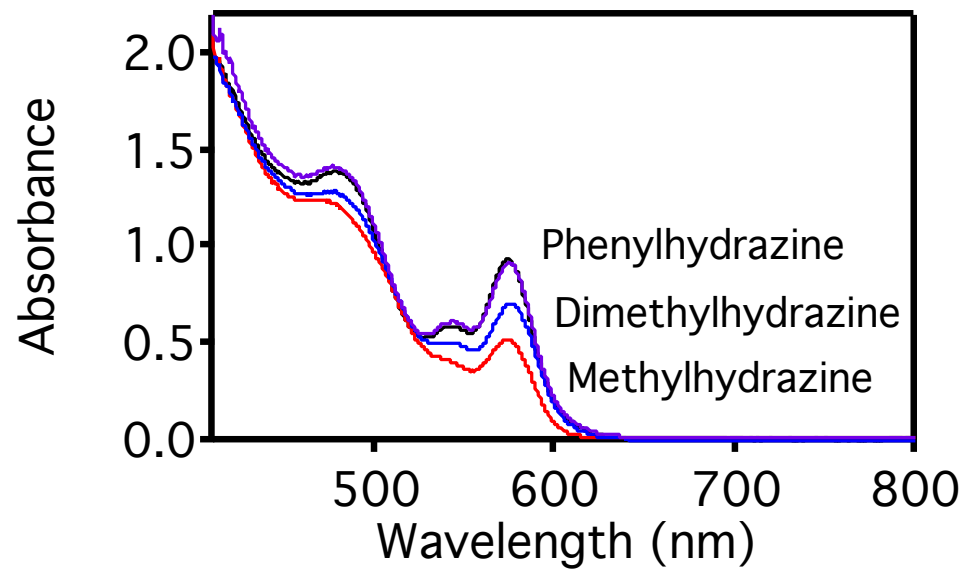

Figure S14. Absorption spectra of mixtures of CdSe QDs ( $d \sim 5.7 \mathrm{~nm}, 20 \mu \mathrm{M}, 0.7 \mathrm{~mL})$ and $10 \mu \mathrm{L}$ neat substituted hydrazine reagent after photoexcitation.

\section{References}

[1] García-Rodríguez, R.; Liu, H. Chem. Commun. 2013, 49, 7857-7859.

[2] Chen, O.; Chen, X.; Yang, Y.; Lynch, J.; Wu, H.; Zhuang, J.; Cao, Y. C. Angew. Chem. Int. Ed. 2008, 47, 8638-8641.

[3] Rinehart, J. D.; Schimpf, A. M.; Weaver, A. L.; Cohn, A. W.; Gamelin, D. R. J. Am. Chem. Soc. 2013, 135, 18782-18785.

[4] Yoshimatsu, M.; Sato, T.; Shimizu, H.; Hori, M.; Kataoka, T. J. Org. Chem. 1994, 59, 10111019. 